\title{
Estudo sociolinguístico da língua Kinikinau
}

A sociolinguistic survey on the Kinikinau language

\author{
Andérbio Márcio Silva MARTINS* \\ Faculdade Intercultural Indígena, Universidade Federal da Grande Dourados \\ (FAIND/UFGD) \\ Gabriel Barros Viana de OLIVEIRA** \\ Programa de Pós-Graduação em Letras, Faculdade de Comunicação, Artes e Letras, \\ Universidade Federal da Grande Dourados (PPG-Letras/FACALE/UFGD)
}

\begin{abstract}
RESUMO: Trata-se de um estudo sociolinguístico sobre a língua Kinikinau, uma língua Aruák a caminho da extinção, falada por um povo também conhecido como Kinikinau, localizado atualmente no sul do Pantanal, no estado do Mato Grosso do Sul. Buscamos descrever seu nível de vitalidade, bem como a falta de sua transmissão às gerações mais jovens e o seu papel simbólico para os falantes em sua relação com o território tradicional. Também objetivamos discutir as perspectivas de revitalização desse idioma indígena. Para lograr tais desideratos, utilizamos métodos colaborativos, de forma que o pensamento e a lógica Kinikinau fossem levados a sério em nossa pesquisa. Por fim, apresentamos um diagnóstico sociolinguístico da língua Kinikinau.
\end{abstract}

PALAVRAS-CHAVE: Estudo sociolinguístico. FamíliaAruák. Língua Kinikinau.

ABSTRACT: This is a sociolinguistic study on the Kinikinau, an Aruák language in the way of extinction spoken by a people also known as Kinikinau, currently located in the south of the Pantanal, state of Mato Grosso do Sul. We seek to describe the level of vitality of the Kinikinaulanguage, the lack of its transmission to younger generations and its symbolic role for the speakers and their traditional territory. We also intend to discuss the chances of this indigenous language revitalization. To achieve such desiderata, we have used collaborative methods, so that Kinikinau thought and logic were actually taken seriously in our survey. Finally, we present a sociolinguistic diagnosis of the Kinikinau language.

KEYWORDS:Sociolinguistic study. Arawakan family. Kinikinau language.

\footnotetext{
* Doutor em Linguística. Universidade de Brasília, Instituto de Letras, Departamento de Linguística, Português e Línguas Clássicas, Brasília, DF. E-mail para contato: anderbiomartins@ufgd.edu.br.

** Mestre em Letras. Universidade Federal da grande Dourados, Faculdade de Comunicação, Artes e Letras, Dourados, MS. E-mail para contato: gbarros341@gmail.com.
} 


\section{Introdução}

A língua Kinikinau foi classificada por Aikhenvald (1999) como um membro independente da família linguística Aruák, falada unicamente em território brasileiro, no pantanal sul-mato-grossense. Embora a pesquisadora a tenha considerado como uma língua, alguns estudiosos têm apresentado o Kinikinau como uma variedade linguística diatópica da língua Terena ${ }^{1}$, também falada no mesmo território, mas sendo este povo expressivamente mais numeroso e com uma história de migração diferente da dos Kinikinau, pois ainda no Chaco paraguaio eram reconhecidos como membros de um grande agrupamento, denominado Guaná (CASTRO, 2011).

Como até o presente momento não há comprovação linguística cabal que justifique considerar o Kinikinau um dialeto do Terena, e considerando ainda equívocos já registrados quando se trata deste povo e da sua forma de se expressar linguisticamente ${ }^{2}$, assumimos a posição de que o Kinikinau é uma língua independente, seguindo Aikhenvald (1999). Cabe observar que nenhum estudo de comparação rigorosa, alicerçado nos princípios do Método Histórico-Comparativo foi realizado sobre a família linguística Aruák, tão pouco entre Kinikinau e Terena, até o presente momento. Loukotka (1968) realizou sua comparação com base em uma lista de 45 palavras. Payne (1991) utilizou o critério de retenções lexicais para classificar as línguas Aruák. Campbell (1997) seguiu a classificação de Kaufman (1994) que, por sua vez, muito se beneficiou da classificação de Loukotka (1968). Aikhenvald (1999) classificou as línguas Aruák com base, predominantemente, em critérios geográficos. Por fim, Souza (2008) se valeu de critérios impressionísticos (look-alike) para afirmar que Kinikinau é uma língua independente dentro da família Aruák, não sendo Terena, embora geneticamente muito próxima dessa. Fabre (2017) e Carvalho (2016) consideram o Kinikinau como um dialeto da língua Terena, mas o primeiro apenas estipula isso, sem realizar nenhum estudo comparativo em seu trabalho. O segundo, realiza uma comparação de caráter inicial, tomando por base somente um elemento

\footnotetext{
${ }^{1}$ Carvalho (2016) e Fabre (2017) apresentam o posicionamento de que o Kinikinau é um dialeto.

2 Por muito tempo, entre os estudiosos das línguas indígenas sul-americanas, a língua Kinikinau foi considerada extinta e se pensou que seus falantes teriam passado a falar uma língua Guaicuru. Isso se deve ao equívoco cometido por Fonseca (1899), que tomou um falante de Kadiwéu como falante de Kinikinau. Essa posição foi seguida por Mason (1946) em seus estudos classificatórios sobre as línguas indígenas sul-americanas.
} 
gramatical - os pluralizadores compartilhados por Kinikinau e Terena, sem comparações lexicais; o que, a nosso ver, não é o suficiente para uma posição conclusiva de que o Kinikinau seja um dialeto Terena.

Por esses motivos, assumimos, para o momento, que a língua Kinikinau é uma língua da família Aruák, geneticamente muito próxima da língua Terena, mas não um dialeto desta. Infelizmente, até o presente, há poucos trabalhos descritivos do Terena e do Kinikinau. Até o dado momento também não temos disponível estudos que tenham descrito com profundidade a gramática dessas duas línguas. Nesse sentido, consideramos que ainda há muito para se pesquisar, a fim de se conseguir compreender melhor esses sistemas. Enquanto isso, tomamos como ponto de partida o que os próprios falantes assumem: dois povos, cada qual com sua própria língua, e, sem sombra de dúvidas, geneticamente relacionadas. Dentro dessa perspectiva, assumimos uma posição que vai ao encontro do processo de valorização da diversidade linguística, seguindo as políticas linguísticas das últimas décadas para as línguas indígenas brasileiras, sem causar qualquer prejuízo de caráter linguístico às propostas de classificação existentes no que se refere ao Terena e ao Kinikinau. O que constitui, na verdade, uma hipótese de trabalho, para a qual optamos por partir da percepção dos falantes nativos representantes desses dois povos, o que nos dá uma certa liberdade para considerar, como ponto inicial, a existência de duas línguas na atualidade, e não variações dialetais de uma única. Desse modo, consideramos que nossa posição não obedece a um critério político em detrimento de um critério linguístico, mas apenas reforça a necessidade de estudos descritivos e histórico-comparativos mais aprofundados acerca da família Aruák como um todo.

Buscamos também, com esse nosso posicionamento, chamar a atenção para o nível de vitalidade da língua Kinikinau. Para melhor compreensão do assunto apresentado, tratamos inicialmente da vitalidade da língua, considerando sua transmissão, a relação entre língua e território e as perspectivas de revitalização linguística, tudo dentro da realidade sociolinguística atual, com dados levantados em campo durante os anos de 2016 e 2017, período de realização do Mestrado em Letras no Programa de Pós-Graduação em Letras da Universidade Federal da Grande Dourados.

Como fruto de trabalho de campo junto aos Kinikinau, apresentamos um diagnóstico sociolinguístico, que expressa exatamente o estado atual da língua, tendo 
sido para isso fundamental as leituras realizadas de Campbell (1997) e Campbell e Muntzel (1989) sobre o tratamento de dados de línguas com risco eminente de extinção. Paraa elaboração de um diagnóstico sociolinguístico da língua Kinikinau, utilizamos como suporte teórico e metodológico, estudos realizados por alguns pesquisadores reconhecidos por discutirem e produzirem trabalhos dessa natureza, como Labov (1994), Thomason (2001), além de Maher (1996, 2007, 2008), Aquino (2010) e Viegas (2014).

\section{Nível atual de vitalidade da língua Kinikinau}

Como pudemos constatar em trabalho de campo, a língua Kinikinau atualmente é uma língua moribunda ${ }^{3}$, a ponto de deixar de ser falada. Possui três falantes que se encontram relativamente isoladas umas das outras, duas morando na aldeia Mãe Terra, município de Miranda-MS, e outra morando na aldeia São João, Porto Murtinho-MS. O número de semi-falantes (fortes ou fracos) é também reduzido, não indo além de 20 indivíduos, na mais otimista das estimativas. O número de lembradores já é um pouco maior, entre 50 e 150. Aqui também temos uma estimativa. Tratamos aqui como estimativas pois, devido ao espalhamento em que os Kinikinau se encontram, torna-se tarefa quase impossível estipular números exatos, uma vez que não existe censo organizado para atender tal necessidade. Cabe destacar que a proposta de classificação dos falantes de língua Kinikinau, segundo sua proficiência, foi fundamentada em Campbell e Muntzel (1989). Dessa forma, consideramos falantes quem fala e entende Kinikinau; semi-falantes fortes quem não fala a língua, mas entende tudo o que um falante fala na língua; semi-falantes fracos quem não fala a língua, mas a entende um pouco do que um falante fala na língua; e lembradores: quem sabe uma ou outra palavra e algumas frases do idioma Kinikinau, mas não entende a língua plenamente.

De acordo com os nossos colaboradores e com o que pudemos observar in situ, as três falantes possuem mais de 65 anos de idade. Chamamos essa parcela da população Kinikinau de Geração 1. Todos os membros da Geração 1 são falantes de Kinikinau. Em seguida, temos os filhos da Geração 1, a qual chamamos de Geração 2.

\footnotetext{
${ }^{3}$ Entendemos aqui como moribunda uma língua que conta com menos de 10 falantes (CAMPBELL, 1997).
} 
A faixa etária da Geração 2 varia entre 40 e 65 anos. Em sua grande maioria, os membros da Geração 2 são semi-falantes fortes da língua Kinikinau, isto é, eles entendem tudo o que a Geração 1 fala na língua ancestral, contudo não conseguem falála. Há também na geração 2, numa minoria diminuta, semi-falantes fracos, ou seja, pessoas que, como os semi-falantes fortes, também não falam Kinikinau, todavia não conseguem entender tudo que um falante da Geração 1 fala, se restringindo apenas a algumas orações simples contextualizadas, algumas perguntas, além de possuírem amplo domínio do vocabulário básico da língua Kinikinau ${ }^{4}$. A Geração 3, filhos da Geração 2 e netos da Geração 1, possuem faixa etária entre 15 e 40 anos e se dividem entre semi-falantes fracos e lembradores (quem conhece uma ou outra palavra ou frase Kinikinau e não entende nada que um falante fala), com maioria esmagadora destes sobre aqueles nessa parcela da população Kinikinau. A Geração 3 representa a parcela mais escolarizada da população Kinikinau. Por fim, temos a Geração 4, os bisnetos da Geração 1, todos com idade inferior a 15 anos. Aqui, no máximo, temos lembradores da língua Kinikinau, que aprenderam o pouco que sabem do idioma ancestral na escola da Aldeia São João, com um professor semi-falante forte da Geração 2. Dessa forma, já é possível ter uma dimensão do nível de vitalidade crítico que se encontra a língua Kinikinau, que é uma situação de língua moribunda, prestes a se tornar nolensvolens uma língua morta ${ }^{5}$. Para compreender a lamentável situação descrita, é preciso compreender melhor o contexto histórico e social do povo Kinikinau, o que nos leva a considerar que a perda do território foi a primeira e a principal causa da perda gradativa e acelerada da função social da língua nativa.

Após a Guerra do Paraguai (1864-1870), os Kinikinau foram expulsos do território tradicional que ocupavam à beira do córrego Agachi. A remoção forçada se iniciou imediatamente após o referido conflito platino e se concretizou no início da

\footnotetext{
${ }^{4}$ Entendemos aqui vocabulário básico no sentido como esse termo é entendido na Linguística Histórica, por linguistas como Campbell (2013), Antilla (1972), Hock (1991), entre outros: um domínio do léxico menos suscetível a ser tomado por empréstimo entre as línguas, como nomes de partes do corpo, termos de parentesco, verbos básicos, nomes de cores e nomes de elementos da natureza.

${ }^{5}$ A partir de Hinton (2013) e Hinton \& Hale (2001), entendemos aqui nesse trabalho que uma língua, ao deixar de ser falada, pode entrar em duas categorias: 1) a das línguas adormecidas, ou seja, línguas não mais faladas, mas que possuem registros e descrições consideráveis, o que possibilita futuras empreitadas de revitalização, a partir desses trabalhos. Um exemplo que podemos dar para ilustrar o que chamamos aqui de língua adormecida é o Latim; 2) línguas mortas, ou seja, línguas não mais faladas e com parcos ou inexistentes registros e descrições, o que impossibilita sua revitalização futura. Um exemplo são as línguas charruanas (Charrua, Balomar, Chaná e Güenoa).
} 
década de 1940. É possível estimar que até meados do século XX a língua Kinikinauainda era falada por $100 \%$ da comunidade Kinikinau que, por sua vez, já era bilíngue (Kinikinau-Português), conforme nós podemos depreender de cronistas como Leverger (1845) e Taunay (1940), além de informações colhidas em nosso trabalho de campo. Porém, concluídaaretirada de suas terras por agentes do Estado brasileiro e destruída a última aldeia Kinikinau, com a expulsão da Geração 0 (os pais e avós da Geração 1) das margens do Agachi, começa o início do que parece ser o "fim" da língua Kinikinau. A Geração 0 transmitiu a língua ancestral para a Geração 1, mesmo sendo obrigados agora a morarem em outras comunidades de fala, seja elas Terena, Kadiwéu ou não indígena. A partir disso a língua Kinikinau passa a perder a função social para o grupo, assim como nos afirmaram alguns dos Kinikinaus entrevistados durante a nossa pesquisa de campo. Portanto, apartir de 1940, a língua Kinikinau passa a ser vista como algo sem sentido de continuar existindo e sem função prática.

Ao serem deportados para outras terras (Kadiwéu, Terena e não indígenas), rapidamente perceberam que a língua nativa não teria mais uma função comunicativa para eles, pois torna-se missão extremamente difícil para uma língua ter uma função comunicativa sem uma comunidade de fala e com funções sociais cada vez mais restritas, visto que a sociedade Kinikinau passa a não existir mais. O que passa a existir, de fato, são grupos familiares Kinikinau isolados, que apenas se afirmam Kinikinau endogamicamente, inseridos em sociedades Terena, Kadiwéu e não indígena.

Como forma inevitável de sobrevivência, os Kinikinau adotaram o Português como língua de comunicação. Somente no final da década de 1990, os Kinikinau acordaram sua identidade étnica adormecida (DA SILVA; SOUZA, 2003). Melhor dizendo, fizeram gritar sua identidade silenciada pelo Estado. A partir daí surge o interesse e uma opinião favorável sobre a sua própria língua, embora ela continue destituída de uma função social-comunicativa. A partir disso, a língua Kinikinau passa a não ser considerada mais um peso, algo prejudicial e sem função. Passa a ser vista como uma ferramenta muitíssimo importante para auxiliar na luta política, por facilmente acentuar sua diferença em relação ao outro (lembrando que os Kinikinau buscam se autoafirmar dentro do cenário multiétnicosul-matogrossense) e afirmar sua indianidade Kinikinau para os puxarara ${ }^{6}$, a qual a todo instante é posta à prova e deve ser 
reafirmada incessantemente, pela força das circunstâncias. Contudo, o movimento começou tarde para a língua, os falantes já eram bem poucos e espalhados. Uma comunidade de fala já não existia mais, visto que, paulatinamente, os Kinikinau viram seu território tradicional encurtando sob a sanha pecuniária dos caudilhos puxarara. $\mathrm{O}$ território tradicional estava, e ainda está, para ser retomado. Lutar pelo território concomitantemente ou posteriori à luta pela revitalização da língua ancestral é impossível para os Kinikinau, conforme eles nos disseram à exaustão, em um ano e meio de convivência. Primeiro o território, o sagrado, o sonhado, o necessário.

Recentemente, uma das últimas falantes do Kinikinau, Dona Ágda Roberto ${ }^{7}$, mudou-se da São João para a aldeia Mãe Terra, lá encontrando-se com sua mãe, Dona Zeferina Moreira, a principal falante da língua nativa. Esse fato pode acalentar um fio de esperança para o futuro da língua Kinikinau, visto que as duas só interagem entre si no idioma ancestral.

A língua, nesse sentido, não é mais transmitida em sua plenitude às gerações mais novas há pelo menos 60 anos, o que corresponde a três gerações desse povo. $\mathrm{O}$ motivo da interrupção, provavelmente se deve à perda territorial, ao espalhamento dos falantes, ao esfacelamento da comunidade de fala, à necessidade de falar português e à restrição de uso da língua, do ponto de vista social. Além disso, durante o período pósguerra, como estratégia de sobrevivência, tiveram que silenciar a sua identidade kinikinau, tendo sido dado como grupo extinto, passando a viver entre os Terenas, Kadiwéu e não indígenas. Há fator mais forte de identidade que a língua? Nesse sentido, uma das primeiras estratégias de sobrevivência adotada pelos Kinikinau foi silenciar sua própria língua, pois, sendo falada, poderia lhes conferir uma identidade étnica que naquele momento não surtiria um efeito positivo.

No final da década de 1990, sob influência do ambiente amigável para as minorias, proporcionado pela Constituição Federal de 1988, começa um momento favorávelaos Kinikinau para reassumirem sua identidade étnica, que foi mantida por muito tempo silenciada como estratégia de sobrevivência (DA SILVA; SOUZA, 2003).

\footnotetext{
${ }^{6}$ Puxarara significa 'não-indígena' no idioma Kinikinau.

7 Dona Ágda adquiriu a língua Kinikinau por intermédio de seus avós maternos. Quando pequena, convivia muito com os seus avós maternos, especialmente a sua avó, Dona Francisca Pereira. Ouvindo os dois anciãos conversarem e conversando com a sua avó Dona Ágda aprendeu o idioma Kinikinau. Sem os seus avós maternos, ela o não teria aprendido, visto que sua mãe não lhe ensinou o idioma ancestral.
} 
E é exatamente isso o que fazem. Assumem-se como Kinikinau perante outros povos indígenas e, principalmente, perante o Estado brasileiro. Com isso, começam a lutar pelos seus direitos garantidos por nossa Carta Magna, como o direito de usufruir seu território Kinikinau. Então, a língua Kinikinau ganha um alto prestígio, volta a ter valor. Passa a ser vista como uma ferramenta para a luta política ${ }^{8}$ bastante eficiente, por "provar", por assim dizer, principalmente aos olhos dos não indígenas, a indianidade desse povo e sua identidade étnica. Contudo, atualmente a língua Kinikinau não passa disso, de uma ferramenta para a luta política, de importância análoga a outras ferramentas, como a Dança Kinikinau e a confecção de cerâmica. Ela não volta a ter uma função social-comunicativa. Afinal, os Kinikinau continuam imersos em comunidades de fala Terena, Kadiwéu e não indígena, não conseguem se organizar enquanto sociedade por não conseguirem se territorializar. Daí o motivo de ela não voltar a ser transmitida pelos falantes às gerações mais novas, apesar de agora ser muitíssimo valorizada.

A expulsão do seu território tradicional colocou os Kinikinau em situação bastante incômoda, obrigando-os a morarem em terras de outras etnias ou em cidades. Além disso, eles foram completa e deliberadamente invisibilizados pelo Estado brasileiro, que propositalmente os declarou extintos. Assim, os Kinikinau, por estratégia de sobrevivência, visto estarem cientes de que foram declarados extintos pelo Estado e por temerem alguma represália do grupo étnico dono da terra na qual foram morar, começaram a silenciar sua identidade étnica (DA SILVA; SOUZA, 2003). Para lograr tal desiderato, a primeira atitude adotada por esses indígenas foi silenciar a língua Kinikinau. De acordo com eles, se estavam morando em terras estrangeiras, por que ensinar a língua ancestral aos seus filhos? O que só atrapalharia a integração das crianças na nova comunidade. E se o Estado lhes falava que não existiam mais, por que ensinar seus filhos a falarem Kinikinau, sob o risco de o Estado expulsá-los da terra da outra etnia em que eles moravam, por não serem da referida etnia? Ou pior ainda, deportá-los para a periferia de alguma cidade, pois se assumindo como Kinikinau automaticamente lhes imputaria uma condição de não-indígena perante o Estado, pois se os Kinikinau estavam extintos, não tinha como alguém ser índio Kinikinau, pois esses agora ex-índios haviam perdido sua indianidade, e a indianidade não era algo que se

\footnotetext{
${ }^{8}$ Entende-se aqui luta política como luta para retomar o território tradicional.
} 
perdia e depois a achava. Só se deixava de ser índio e nunca o voltava a sê-lo. Além disso, a expulsão do território no Agachi foi muito violenta, causando traumas a Geração 0 e Geração 1, que fez com que eles associassem o fato de terem sido expulsos de lá por serem Kinikinau. Dessa forma, nada melhor que ensinar os filhos a silenciarem a "Kinikinauidade" deles, e o primeiro passo para ensinar esse silenciamento é não ensinar a língua.

Alguém poderia supor que a perda territorial não tenha sido um fato preponderante, pois, afinal, muitos deles conseguiram se reterritorializar na aldeia São João. Eles poderiam, e tinham todas as condições para fazê-lo, ter construído uma comunidade de fala na aldeia São João, e assim transmitir a língua Kinikinau para as gerações mais novas. O fato é que os Kinikinau nunca se territorializaram nessa aldeia, poia nunca a viram como um lugar deles, onde eles pudessem (re)fundar suas famíliastronco ${ }^{9}$, ou seja, construir um lugar de socialidade Kinikinau. A aldeia São João sempre foi vista como um lugar provisório, um lugar em que eles pudessem se reorganizar, se recuperar da estocada quase mortal do Estado brasileiro. Recuperados, fortalecidos, a intenção dos Kinikinau sempre foi voltar para o território tradicional nas margens do córrego Agachi. Um exemplo do que acabamos de expor temos na fala de Dona Flaviana Roberto: "Casa de Kinikinau é um barraco, porque Kinikinau não tem território e nós não "pretende" fazer uma casa boa. Nós não "tem" previsão de ficar aqui não" (F. ROBERTO, 2016). Desse modo, enquanto não recuperarem o território tradicional, para se reterritorializarem, refundarem suas famílias-tronco, enfim, construir um lugar de socialidade Kinikinau, a língua Kinikinau não terá chances de voltar a ter uma função social-comunicativa para os indígenas Kinikinau.

Além de os Kinikinau não reconhecerem o espaço da aldeia São João como território próprio, eles estavam numa situação de subjugo, o que deve ter contribuído fortemente para não conseguirem se reestruturar territorial e linguisticamente. A prova é a postura atual desses indígenas. A reemergência identitária resultou na autovalorização étnica e na busca da retomada do território tradicional.

Não há dúvidas de que os Kinikinau têm bem claro hoje em dia a importância de sua língua ancestral, principalmente pelo fato de ela ser vista como uma eficiente

\footnotetext{
9 Para a noção de "fundação" e "famílias-tronco" que utilizamos aqui com os Kinikinau, veja Pereira (2009).
} 
ferramenta para sua luta política. Mas é fato também que a retomada do território tradicional é questão prioritária para esse povo e que a preocupação com a revitalização da língua Kinikinau parece ser, por conta da realidade, algo secundário. Entretanto, acreditamos que esperar estar dentro do território tradicional para depois encarar a questão da morte linguística pode ser muito tarde para a língua Kinikinau. É claro que sem o território tradicional é difícil fazer com que a língua volte a ter uma função social-comunicativa. O território tradicional poderia reunir os indígenas, e essa resultante seria favorável. Contudo, como anda a situação política do nosso país, principalmente no tocante aos povos indígenas, parece pouco provável que os Kinikinau consigam o território tradicional a curto prazo.

De um ponto de vista bastante otimista, acreditamos ser possível que a língua possa passar por um processo de revitalização. Afinal, ainda conta com falantes plenos e possui um número considerável de semi-falantes. As gerações mais jovens, principalmente os nascidos depois de 2000, atribuem um grande valor à língua Kinikinau, têm orgulho dela, têm vontade de aprendê-la. Agora, colocar em prática um plano de revitalização da língua Kinikinau, levando em considerações a situação do povo Kinikinau, não nos parece ser uma tarefa fácil dentro da realidade atual dos povos indígenas do Brasil.

\section{Diagnóstico sociolinguístico}

Para a realização da pesquisa com o objetivo de diagnosticar a realidade sociolinguística atual dos Kinikinau, elaboramos um questionário a partir de Maher (2007), Aquino (2010) e Viegas (2014), como pode ser visto em Oliveira (2017). Esse questionário privilegiou uma amostragem representativa e qualitativa, ou seja, não probabilística e não quantitativa, de forma que não foi aplicado em toda a população Kinikinau residente na Aldeia Mãe Terra e na Aldeia São João. Seu foco foi a dinâmica social das línguas em convívio nessas duas comunidades, Mãe Terra e São João, e cumpriu com os seguintes objetivos: a) observação de qual língua - Português, Kinikinau, Terena ou Kadiwéu - é utilizada pelos índios Kinikinau em diferentes situações comunicativas ocorridas dentro e fora da área indígena; b) realização de um levantamento das práticas de letramento que ocorrem na aldeia; c) entrevistas com 
diferentes membros da comunidade, de diferentes faixas etárias e de ambos os sexos, por onde pudemos verificar as competências orais e escritas dos indivíduos, bem como sua atitude em relação às línguas Portuguesa, Kinikinau, Terena ou Kadiwéu; d) observação de 5 famílias com crianças pequenas da comunidade, para registrar que língua está sendo transmitida para as gerações mais novas.

A aplicação dos questionários referentes a esse diagnóstico linguístico foi feita por um dos autores dessa pesquisa durante os meses de outubro de 2016 e março de 2017. Pudemos entrevistar líderes Kinikinau, anciãos falantes da língua, jovens engajados na luta política desse povo e profissionais da área de saúde. Objetivamos, durante a aplicação desses questionários, envolver a comunidade Kinikinau em nossa pesquisa, de forma a estimular reflexões sobre questões como a atual situação da língua Kinikinau, seu uso e transmissão; se essa língua pode deixar de ser falada, entre outras questões. Gravamos todas as entrevistas realizadas. Buscamos, além da aplicação pura do questionário e da realização de entrevistas, valer-nos da observação direta para a realização do diagnóstico que apresentamos a seguir. Valemo-nos da observação direta, de forma que pudéssemos confrontar a nossa percepção com a percepção do indígena, para, a partir daí, chegarmos nas respostas de nossas perguntas, nas conclusões de nosso diagnóstico. O estudo levou em consideração as atitudes linguísticas dos Kinikinau; as práticas de leitura e escrita; a aprendizagem da língua; as aulas de língua Kinikinau na aldeia São João; os usos linguísticos dos Kinikinau nas mais variadas situações comunicativas; os usos linguísticos no âmbito familiar; e os lugares onde os Kinikinau acham que poderiam fazer uso da língua.

Sobre as atitudes linguísticas dos Kinikinau, os resultados de nossa pesquisa demonstram que, a cada dia, a língua goza de bastante prestígio entre os que se declaram Kinikinau. Desse modo, não há nenhum indígena dessa etnia não-falante da língua ancestral que não gostaria de ter adquirido a língua indígena. Em relação à qual língua é a mais bonita, aproximadamente metade dos nossos entrevistados acreditam que o idioma indígena é o mais bonito; a outra metade acredita que a língua Kinikinau é tão bonita quanto a Portuguesa. Sobre se a língua Kinikinau pode desaparecer ou não, nossos entrevistados responderam que não a veem desaparecendo, embora admitam que ela se encontra em perigo e que precisa ser alvo de uma política linguística voltada para a sua revitalização/fortalecimento. Acreditamos que a ampliação do ensino dessa língua 
na escola indígena seja um dos caminhos para isso, no entanto, é necessário antes o acesso ao território tradicional que lhes foi roubado.

Não há nada na cultura indígena (material e espiritual) que os Kinikinau gostariam de mudar. Para eles, há de preservar, pois a cultura deles "veio dos antigos" (ROBERTO, 2017). O que eles gostariam de preservar para as próximas gerações são a produção de cerâmica, a Dança Kinikinau e a língua. Esses três elementos culturais são as três principais ferramentas utilizadas pelos Kinikinau para lutar sua luta política.

As práticas de leitura e escrita existentes entre os Kinikinau são: cartas, bilhetes, jornais, revistas, cartazes, avisos, materiais religiosos (Bíblias, panfletos, hinários), histórias, mitos, anotações pessoais, relatórios de viagem e de reuniões, atas de reuniões, notícias, tarefas escolares, letras de música e livros. As cartas, os bilhetes, os cartazes, os avisos, as histórias, os mitos, as anotações pessoais, as tarefas escolares e os livros ocorrem em sua esmagadora maioria em Português. Os jornais, as revistas, os materiais religiosos, os relatórios de viagens e de reuniões, as atas de reuniões, as notícias e as letras de música ocorrem apenas em Português. Não há uma só prática de leitura ou de escrita que ocorra mais, igualmente ou apenas em Kinikinau

Como sabemos, a língua Kinikinau não é mais transmitida no âmbito familiar há pelo menos três gerações, ou seja, os mais velhos não ensinam os mais jovens o idioma ancestral dentro de casa há mais de 60 anos. O que se tem de aprendizagem da língua Kinikinau são as aulas semanais na escola da aldeia São João, que são ministradas por um professor que não é falante pleno. A escola é o único lugar, segundo os próprios Kinikinau, onde se tem, de alguma forma, o aprendizado da língua nativa. E é somente a escola da São João. Nas escolas das outras aldeias onde há Kinikinau morando, como a aldeia Cabeceira ou aldeia Mãe Terra, não há a presença da língua Kinikinau. Vale ressaltar que as aulas de Kinikinau na escola da São João são bem recentes (menos de 15 anos).

A escola da aldeia São João tem um papel preponderante para o alto número de lembradores da língua Kinikinau, comparado com o baixíssimo número de falantes e semi-falantes. Lá ocorrem aulas de Kinikinau, com um professor que é semi-falante forte da língua. Assim, muitas crianças acabam aprendendo um pouco de seu idioma ancestral, como nomes de partes do corpo, termos de parentesco, nomes de elementos da natureza, de plantas, animais, alimentos e expressões de cumprimento. Sem a escola, 
essas crianças, provavelmente, não teriam aprendido um vocabulário, pois muitas delas são filhas de lembradores e semi-falantes fracos, que dificilmente transmitem o pouco que sabem de Kinikinau para as gerações mais novas, e possuem pouco ou nenhum contato com os anciãos que falam o idioma. A escola da aldeia São João, obviamente, não conseguiu formar nenhum falante de Kinikinau como segunda língua. Contudo, sua atuação em relação à língua é positiva, pois propicia que muitos jovens Kinikinau sejam pelo menos lembradores da língua ancestral de seu povo.

Cabe ressaltar que, até o presente momento, os Kinikinau não contam com nenhum material ou estratégia de revitalização da língua. Não há, segundo eles, nenhuma medida sendo feita para evitar a morte do idioma ancestral. Nenhuma discussão sobre medidas para salvar a língua Kinikinau é realizada em reuniões internas da comunidade, conforme nossos entrevistados nos relataram, embora seja consenso entre eles da importância da língua. Nesse sentido, nenhum deles demonstrou desejo de que a língua de seus antepassados deixe de ser falada, ou seja, desapareça.

Sobre os usos linguísticos dos Kinikinau no âmbito de várias situações comunicativas, compreendemos que o português aparece exclusivamente nas seguintes situações comunicativas no seio da comunidade: nas cerimônias religiosas, nas pescarias, nas caçadas, nas brincadeiras das crianças e nas atividades da roça. A língua portuguesa aparece sozinha nas cerimônias religiosas porque os Kinikinau não contam com nenhum pastor falante de idioma; e porque o padre que, de vez em quando, ia na São João era puxarara e não falava Kinikinau. Nas pescarias e nas caçadas, a língua Kinikinau não aparece devido ao fato de essas atividades serem tarefas masculinas, e hoje em dia não há nenhum falante de Kinikinaudo sexo masculino. Acreditamos que a falta de conhecimento da língua por parte dos homens se dá, provavelmente, por terem sido os primeiros a perdê-la, uma vez que necessitavam desde cedo muito mais da língua portuguesa do que as mulheres, para trabalhar e se relacionar com falantes de língua portuguesa. As mulheres, por outro lado, permaneciam mais tempo em casa, o que possibilitava um acesso à língua a partir do uso que se fazia dela no âmbito familiar, ainda quando criança.

Nas atividades da roça, a ausência do idioma indígena se explica porque todos os falantes de Kinikinau atualmente contam com idade bastante avançada, o que lhes impossibilita o árduo trabalho nas roças, trabalho esse relegado aos mais jovens, que já 
não falam mais a língua Kinikinau. Nas seguintes situações comunicativas, o português aparece em concomitância com o Kinikinau, sendo a língua indo-europeia muitíssimo mais usada que a língua indígena: reuniões internas, reuniões com a participação de não indígenas e indígenas de outras etnias, nas festas tradicionais, na confecção de artesanato/cerâmica e nas rodas de mate e tereré. A língua ancestral somente aparece nas situações descritas aqui se algum dos falantes estiver presente, e mesmo assim sua presença é muito tímida em relação à língua portuguesa.

Um fato interessante é que todos os Kinikinau entrevistados, incluindo os semifalantes fortes, fracos, lembradores e pessoas que desconhecem por completo a língua ancestral admitiram já ter sonhado em Kinikinau, com eles falando no idioma indígena no sonho. Os falantes tendem a sonhar mais em Kinikinau, conforme nos disseram. Já o restante do povo tende a sonhar mesmo na língua portuguesa.

Os falantes que nós entrevistamos costumavam contar muitas histórias na língua Kinikinau para as gerações mais jovens, mas atualmente não contam mais. Hoje em dia os jovens não têm mais paciência para ouvi-los, conforme os mais velhos. Quando começam a contar uma história, a juventude começa a rir deles. Por isso decidiram parar de contar histórias na língua ancestral para os jovens.

Apresentamos, a seguir, um quadro que sintetiza os usos linguísticos identificados a partir do trabalho de observação e de entrevistas realizadas com cinco famílias Kinikinau: a família da Dona Flaviana Roberto (semi-falante forte), do Sr. Manoel Roberto (semi-falante fraco), da Dona Ágda Roberto (falante), do Sr. Naldemir Flores (lembrador) e do Sr. Nicolau Flores (desconhece totalmente a língua Kinikinau). Acreditamos que os usos linguísticos no âmbito dessas cinco famílias representem a realidade das famílias Kinikinau. Percebe-se claramente o quão tímido é a presença da língua Kinikinau no ambiente familiar e o quão forte é a presença do Português. Não há um só momento, mesmo nas famílias dos falantes, em que se usa somente ou com mais frequência a língua indígena.

LI = Língua Indígena $($ Kinikinau $)$

LP = Língua Portuguesa 
Quadro 1: Usos linguísticos no ambiente familiar dos Kinikinau

\begin{tabular}{|l|l|l|l|c|c|}
\hline & SÓ LI & SÓ LP & LI = LP & MAIS LI & MAIS LP \\
\hline $\begin{array}{l}\text { Língua de interação entre } \\
\text { marido e mulher }\end{array}$ & & & & & X \\
\hline $\begin{array}{l}\text { Língua de interação entre mãe } \\
\text { e filhos }\end{array}$ & & X & & & X \\
\hline $\begin{array}{l}\text { Língua de interação entre pai e } \\
\text { filhos }\end{array}$ & & $\mathrm{X}$ & & & $\mathrm{X}$ \\
\hline $\begin{array}{l}\text { Língua de interação entre avô } \\
\text { e netos }\end{array}$ & & $\mathrm{X}$ & & & \\
\hline $\begin{array}{l}\text { Língua de interação entre avó } \\
\text { e netos }\end{array}$ & & & & $\mathrm{X}$ \\
\hline $\begin{array}{l}\text { Língua utilizada durante as } \\
\text { refeições }\end{array}$ & & & & \\
\hline $\begin{array}{l}\text { Língua utilizada nas } \\
\text { brincadeiras infantis }\end{array}$ & & & & \\
\hline $\begin{array}{l}\text { Língua utilizada nas } \\
\text { brincadeiras tradicionais }\end{array}$ & & & & \\
\hline $\begin{array}{l}\text { Há alguma outra situação no } \\
\text { âmbito de sua família que } \\
\text { você deseje relatar? }\end{array}$ & & & & \\
\hline
\end{tabular}

Os Kinikinau acreditam que a língua indígena poderia ser usada na escola, no lar, nos jogos de futebol, nas reuniões da comunidade (com ou sem presença de nãoindígenas ou indígenas de outras etnias), nas idas à cidade (ex. Campo Grande, Miranda, Bonito), nas brincadeiras (tradicionais e não-tradicionais) das crianças, nas festas da comunidade (como o Dia do Índio), na igreja, nos trabalhos da roça, nas pescarias, nas caçadas, na confecção de artesanato, nas rodas de mate ou tereré, no comércio (para comunicarem entre si) e nas instituiç̃oes do Governo. Hoje como a língua Kinikinau goza de grande prestígio e é vista com bons olhos por esses indígenas, não tem nenhum ambiente específico onde eles achem que a língua ancestral não 
poderia ser usada. Aqui temos fio alentador para se pensar em uma política linguística voltada para a revitalização da língua Kinikinau.

Segundo os nossos colaboradores, eles gostariam de conversar no idioma ancestral com os professores da comunidade, com sua família de modo geral - pai, mãe, irmãos, irmãs, primos, marido, esposa, filhos - com os colegas da escola, com os amigos em geral e com outros Kinikinau que eles não conhecem. Os falantes que nós entrevistamos nos disseram que hoje em dia não conversam com mais frequência em Kinikinau porque é difícil encontrar um outro falante ou uma pessoa que entenda tudo o que falam no idioma (semi-falante forte). Já os não-falantes nos disseram que se eles soubessem ou aprendessem a falar o idioma só conversariam em Kinikinau com qualquer outra pessoa que também falasse ou entendesse a língua ancestral. Essa informação é outro fio alentador para se pensar em uma política linguística voltada para a revitalização da língua Kinikinau, uma vez que ainda há falantes e há indivíduos interessados em aprender a língua.

\section{Considerações finais}

A língua Kinikinau é uma língua moribunda, a ponto de deixar de ser falada.possui atualmente três falantes, que, todavia, se encontram separadas, morando em duas aldeias diferentes. Além desses falantes, a língua Kinikinau conta com aproximadamente 20 semi-falantes (fortes ou fracos) e entre 50 e 150 lembradores.

Encontra-se, portanto, em um nível crítico de vitalidade, e o que ocasionou tal situação foi a perda do território tradicional desses indígenas nas margens do córrego Agachi, tendo como causadores desse fato agentes do Estado brasileiro, tendo sido deportados para territórios de outras etnias indígenas (Terena e Kadiwéu) ou para centros urbanos ou colônias agrícolas A partir de então, a língua Kinikinau passou a perder, de forma acelerada, sua função social e comunicativa. Consequentemente, os Kinikinautiveram que adotar uma língua de sobrevivência, que no caso foi a língua portuguesa. A identidade Kinikinau ficou silenciada, até que o momento propício surgisse, e ela pudesse voltar a ser apresentada. A língua Kinikinau segue existindo, mas para que volte a ser falada em toda sua potencialidade comunicativa, é necessário que os Kinikinau façam um planejamento linguístico voltado para a revitalização da 
língua, caso contrário, a língua indígena constará como mais um item na longa lista de perdas negociadas pelos Kinikinau para continuarem existindo enquanto povo indígena.

Cabe destacar, por fim, que os Kinikianu, embora se apresentem dispostos para pensar e colocar em prática uma política linguística de revitalização, consideram a questão do território tradicional prioridade e a questão linguística algo secundário para o momento, no sentido de que é preciso resolver primeiro a questão fundiária para enfrentar o problema da revitalização da língua. Contudo, por serem duas problemáticas conectadas, acreditamos ser possível assumir o problema da revitalização linguística antes ou concomitantemente à questão do território. Uma questão não anula ou enfraquece a outra. E caso os Kinikinau queiram manter sua língua ancestral viva, sendo falada, urge que eles encarem para já a questão da língua com o mesmo vigor com que encaram a questão do território, caso contrário a língua Kinikinau fatalmente desaparecerá.

\section{REFERÊNCIAS}

AIKHENVALD, A. Y. (1999). The Arawak language family. In: The Amazonian Languages. R.M.W. Dixon; A. Y. Aikhenvald (org.). Cambridge: Cambridge University Press, p. 65-105.

ANTILLA, R. An introduction to historical and comparative linguistics. Nova York: Macmillan, 1972.

AQUINO, L. S. Pesquisas sociolinguísticas entre os Asuriní do Tocantins. Contribuição para o Inventário Nacional da Diversidade Linguística (INDL). 2010. 152 f. Dissertação (Mestrado em Linguística) - Departamento de Linguística, Português e Línguas Clássicas, Universidade de Brasília, Brasília, 2010.

CAMPBELL, L. American Indian Languages: The historical linguistics of Native America. Oxford: Oxford University Press, 1997.

Classification of the indigenous languages of South America. In: CAMPBELL, L.; GRONDONA, V. (org.). The indigenous of South America: a comprehensive guide. Berlim: Mouton de Gruyter, p. 59-166, 2012. 
Historical linguistics: an introduction. 3 ed. Cambridge: The MIT Press, 2013.

CAMPBEL, L.; MUNTZEL, M. C. The structural consequence of language death. In: Dorian, N. C. (org.). Investigating obsolescence: studies in language contraction and language death. Cambridge: Cambridge University Press, 1989.

CARVALHO, F. O. Terena, Chané, Guaná and Kinikinau are one and the same language: Setting the Record Straight on Southern Arawak Linguistic Diversity. Liames, Campinas, v. 16, n. 1, p. 39-57, 2016.

CASTRO, I.De Chané-Guaná a Kinikinau: da construção da etnia ao embate entre o desaparecimento e a persistência. Campinas: Unicamp. 347 f. Tese (Doutorado em Ciências Sociais) - Instituto de Filosofia e Ciências Humanas, Universidade Estadual de Campinas, Campinas, 2010.

FABRE, A. Diccionario etnolingüístico e guía bibliográfica de los pueblos indígenas sudamericanos. Arawak. 2017. Disponível em: <http://www.ling.fi/Entradas\%20diccionario/Dic=Arawak.pdf $>$. Acesso em: 11 de mar. 2017.

FONSECA, J. S. Voyage autour du Brésil. Edition pour les Américanistes. Rio de Janeiro: Librairie A. Lavignasse Filho \& C, 1899.

HOCK, Hans Heinrich. Priciples of historical linguistics. Berlin: Monton de Gruyter. 1991.

DA SILVA, G. José; SOUZA, J. L. O despertar da fênix: a educação escolar como espaço de afirmação da identidade étnica Kinikinau em MS. Sociedade e Cultura,v. 6, n. 2, julho/dezembro, 2003.

KAUFMAN, T. The native languages of South America. In: MOSELEY, C.; ASHER, R. E. (org.). Atlas of the world's languages. London: Routledge, p. 46-76, 1994.

LABOV, W. Principles of Linguistic Change. Volume 1: Internal factors. Oxford: Blackwell Publishers, 1994. 
LEVERGER. Diário do reconhecimento do rio Paraguai desde a cidade de Assunção até o Paraná, 1845. Revista Trimestral do Instituto Histórico, Geográfico e Etnográfico do Brasil. Rio de Janeiro, v. 25, p. 222, 1862.

LOUKOTKA, C. Classification of South American Indian languages. Reference Séries 7. Los Angeles: University of California, 1968.

MAHER, T. M. Ser professor sendo índio: questões de lingua(gem) e identidade. Tese de doutorado. Unicamp, Campinas, SP (inédita), 1996.

Comissão Pró-ìndio do Acre. "Instrumentos Metodológicos para Levantamento Sociolinguístico" (org. Tereza Maher). Projeto Políticas Linguísticas no Acre Indígena. Rio Branco: CPI/Acre, 2007.

Em busca do conforto linguístico e metodológico no Acre indígena. Artigo publicado em Trabalhos em Linguística Aplicada. IEL: Unicamp, 2008.

MASON, J. A. (1946). The languages of South American indians. In: STEWARD, J. H. (Editor). Handbook of South American Indians. Washington: Government Printing Office, $157-317$.

OLIVEIRA, G. B. V. de. LínguaKinikinau - descrição de aspectossociolinguísticos e fonológicos. 2017. 173 f. Dissertação de Mestrado. Programa de Pós-Graduação em Letras da Universidade Federal da Grande Dourados, Dourados-MS, 2017.

PAYNE, D. L. 1991. A classification of maipuran (Arawakan) languages based on shared lexical retentions. In Desmond Derbyshire; Geoffrey K. Pullum (eds.). Handbook of amazonian languages, vol. III, pp. 355-499. Berlin: Mouton de Gruyter.

PEREIRA, L. M. Os Terena de Buriti: formas organizacionais, territorialização e representação da identidade étnica. Dourados: Editora UFGD, 2009.

ROBERTO, A. Ágda Roberto. Depoimento. [21 mar. 2017]. Entrevistador: Gabriel Barros Viana de Oliveira. Dourados, 2017. Arquivo de áudio digital. Entrevista concedida no âmbito do projeto de mestrado desenvolvido por Gabriel Barros Viana de 
Oliveira junto à Faculdade de Comunicação, Artes e Letras da Universidade Federal da Grande Dourados.

ROBERTO, F. Flaviana Roberto. Depoimento. [19 out. 2016]. Entrevistador: Gabriel Barros Viana de Oliveira. Dourados, 2016. Arquivo de áudio digital. Entrevista concedida no âmbito do projeto de mestrado desenvolvido por Gabriel Barros Viana de Oliveira junto à Faculdade de Comunicação, Artes e Letras da Universidade Federal da Grande Dourados.

ROBERTO, M. Manoel Roberto. Depoimento. [17 out. 2016]. Entrevistador: Gabriel Barros Viana de Oliveira. Dourados, 2016. Arquivo de áudio digital. Entrevista concedida no âmbito do projeto de mestrado desenvolvido por Gabriel Barros Viana de Oliveira junto à Faculdade de Comunicação, Artes e Letras da Universidade Federal da Grande Dourados.

RODRIGUES, A. D.; CABRA, A. S. A. C. Revendo a classificação interna da família Tupí-Guaraní. In: CABRAL, A. S. A. C.; RODRIGUES, A. D. (orgs.). Línguas indígenas brasileiras: fonologia, gramática e história. Belém: EDUFPA, 2002, v. 1, p. 327-337.

Koenukunoe Emo 'u: a língua dos índios Kinikinau. Campinas: Unicamp. 196 f. Tese (Doutorado em Linguística) - Curso de Linguística, Instituto de Estudos da Linguagem, Universidade Estadual de Campinas, Campinas, 2008.

TAUNAY, Alfredo D’Escragnolle. Entre nossos índios: Chanés, Terenas, Kinikinaus, Guanás, Laianas, Guatós, Guaycurus, Caingangs. São Paulo: Companhia Melhoramentos, 1940.

THOMASON, S. G. Contact-induced language change and pidgin/creole genesis. In: SMITH, Norval; VEENSTRA, Tonjes (orgs.) Creolization and contact. Amsterdam: Benjamins, pp. 249-262, 2001.

VIEGAS, C. W. Línguas em rede: para o fortalecimento da língua e da cultura Kokama. 2014. 470 f. Tese (Doutorado em Linguística) - Departamento de Linguística, Português e Línguas Clássicas, Universidade de Brasília, Brasília, 2014. 